Methods: This was an international, multicentric, cross-sectional study performed between October 2019 and June 2020 (ClinicalTrial NCT04426747). Consecutive patients were included if they had definite axSpA, RA or PsA, were aged above 18 and able to walk. Barriers and facilitators to physical activity were measured using the 10-item Inflammatory arthritis Facilitators and barriers questionnaire (IFAB) (5). The IFAB ranges -70 to 70 with lower scores indicating more barriers; scores below -5 correspond to significant barriers. Physical activity was measured by the IPAQ-S questionnaire (6). Exploratory analyses used steps per day collected by smartphone, and psychological readiness to change by stages of behavior change. Statistical analysis used Spearman correlation (rho, $p<0.05$ ), Student $T$ test or multivariate analysis using $R$ version 3.5.1. There was no imputation of missing data. Results: Of 245 patients included, 150 had analysable data $(69(46 \%)$ axSpA, $63(42 \%)$ RA, 18 (12\%) PsA). Mean age was 48.6 years (SD 17.1), mean disease duration $11.7(10.1)$ years and $60 \%$ were women. The mean score of barriers and facilitators to physical activity was 6.0 (SD 19.2, median 4) (Figure 1). A total of $39(26 \%)$ patients scored less than -5 , which could justify a targeted intervention. The mean physical activity was 2837 (SD 2668, median 1784) Metabolic Equivalent of Task min per week. Physical activity was correlated with score of barriers and facilitators to physical activity in linear regression (rho $0.28, p<0.001$ ), as well as the stage of behavior change regarding active lifestyle (rho $0.35, p<0.001$ ). No correlation was observed with steps per day (Table 1)

Conclusion: Perceived barriers and facilitators to physical activity are correlated with physical activity. Targeting patients with high barriers and low facilitators to physical activity could be an effective option to improve physical activity levels. REFERENCES:

[1] O'DWYER T., et al. Rheumatology 2014. Vol. 53, n 10, pp. 1812-1817.

[2] OSTHOFF, A et al. 2018. Vol. 77, $\mathrm{n}^{\circ}$ 9, pp. 1251-1260. DOI 10.1136/ annrheumdis-2018-213585.

[3] MARLEY, J, et al: BMC Musculoskeletal Disorders. 2017. Vol. 18, pp. 482. DOI 10.1186/s12891-017-1836-2.

[4] COSTE, N., et al. 2019. DOI 10.1016/j.rehab.2019.07.009.

[5] DAVERGNE, T, et al. Rheumatology International 2020. DOI 10.1007/ s00296-020-04692-4.

[6] LEE, PH, et al. 2011. Vol. 8, pp. 115. DOI 10.1186/1479-5868-8-115.

Table 1 for abstract: correlation between IFAB questionnaire, each items and level of physical activity with or without extreme values

\begin{tabular}{|c|c|c|c|}
\hline Item & $\begin{array}{l}\text { Correlation with } \\
\text { IPAQ-S min/met/ } \\
\text { week, rho }\end{array}$ & $\begin{array}{l}\text { Correlation with } \\
\text { stage of behavior } \\
\text { change, rho }\end{array}$ & $\begin{array}{l}\text { Correlation with } \\
\text { mean steps } \\
\text { per day, rho }\end{array}$ \\
\hline Total IFAB score & 0.28 *** & $0.35^{* * *}$ & 0.08 \\
\hline Item 1 & $0.29^{\star \star \star}$ & 0.16 * & 0.16 * \\
\hline Item 2 & 0.06 & 0.02 & 0.05 \\
\hline Item 3 & 0.08 & 0.16 * & 0.01 \\
\hline Item 4 & 0.13 & 0.09 & -0.07 \\
\hline Item 5 & -0.09 & 0.10 & 0.07 \\
\hline Item 6 & 0.22 ** & $0.25^{\star \star \star}$ & -0.05 \\
\hline Item 7 & $0.22^{* \star}$ & $0.20^{* \star}$ & 0.12 \\
\hline Item 8 & 0.16 * & $0.26^{* \star \star}$ & 0.11 \\
\hline Item 9 & 0.15 & $0.33^{\star \star \star}$ & 0.11 \\
\hline Item 10 & 0.09 & $0.17^{*}$ & 0.02 \\
\hline Social support questions & 0.14 & $0.27^{\star \star \star}$ & -0.03 \\
\hline $\begin{array}{l}\text { Psychological and knowledge } \\
\text { status questions }\end{array}$ & 0.22 ** & 0.16 * & 0.09 \\
\hline
\end{tabular}

${ }^{*}=\mathrm{P}<0.05,{ }^{* *}=\mathrm{p}<0.01,{ }^{* * *}=\mathrm{p}<0.001$

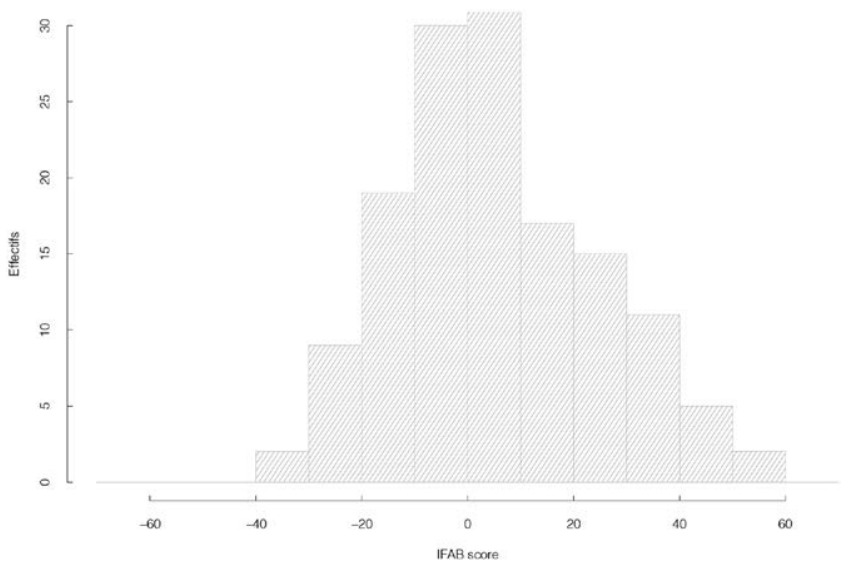

Figure 1. Distribution of the IFAB scoreFootnote: $Y$ axis: effectifs, $X$ axis: IFAB score (possibles values from -70 to 70
Acknowledgements: I have no acknowledgements to declare. We thank the following coinvestigators: Sylvie Rozenberg, Beatrice Banneville, Rachida Inaoui, Emmanuelle Dernis, Athan Baillet and Catherine Beauvais, and we thank Herve Servy for expert CRO advice

Disclosure of Interests: None declared

DOI: 10.1136/annrheumdis-2021-eular.1759

\section{POS0275-HPR CONCORDANCE BETWEEN THE PHYSICIAN'S AND THE NURSE'S ASSESSMENT OF DISEASE ACTIVITY IN RHEUMATOID ARTHRITIS USING DAS-28, CDAI AND SDAI IN SEVEN MIDDLE EASTERN ARAB COUNTRIES}

N. Ziade ${ }^{1,2}$, B. Zorkany ${ }^{3}$, S. Al Emadi ${ }^{4}$, M. Abu Jbara ${ }^{5}$, H. Halabi ${ }^{6}$, S. Saad ${ }^{7,8}$, L. Kibbi ${ }^{9}$, M. Mashaleh ${ }^{10}$, H. Badsha ${ }^{11}$, G. Harifi' ${ }^{11}$, A. Ayko ${ }^{12}$, E. Alam ${ }^{13}$, A. Daher ${ }^{14}$, B. Masri ${ }^{15}$, G. Merheb ${ }^{16,17}$, J. Messaykeh $^{18}$, K. Mroue $^{19}$, N. Salloum ${ }^{20}$, T. Arayssi ${ }^{21} .{ }^{1}$ Saint-Joseph University, Rheumatology, Beirut, Lebanon; ${ }^{2}$ Hotel-Dieu de France, Rheumatology, Beirut, Lebanon; ${ }^{3}$ Cairo University, Rheumatology, Cairo, Egypt; ${ }^{4}$ Hamad Medical Corporation, Rheumatology, Doha, Qatar; ${ }^{5}$ Al-Bashir hospital, Rheumatology, Amman, Jordan; ${ }^{6}$ King Faisal Specialist Hospital, Rheumatology, Jeddah, Saudi Arabia; ${ }^{7}$ Assiut University, Rheumatology, Assiut, Egypt; ${ }^{8}$ King Hamad University Hospital, Rheumatology, Bahrain, Bahrain; ${ }^{9}$ Specialized Medical Center, Rheumatology, Riyadh, Saudi Arabia; ${ }^{10}$ King Hussein Medical Center, Rheumatology, Amman, Jordan; ${ }^{11}$ Dr Humeira Badsha Medical Center, Rheumatology, Dubai, United Arab Emirates; ${ }^{12}$ Heartbeat clinic, Rheumatology, Beirut, Lebanon; ${ }^{13}$ Levant Hospital, Rheumatology, Beirut, Lebanon; ${ }^{14}$ Saint-Joseph University, Family Medicine, Beirut, Lebanon; ${ }^{15}$ Jordan Hospital, Rheumatology, Amman, Jordan; ${ }^{16}$ Holy-Spirit University, Rheumatology, Kaslik, Lebanon; ${ }^{17}$ Notre-Dame des Secours, Rheumatology Jbeil, Lebanon; ${ }^{18}$ Al Monla Hospital, Rheumatology, Tripoli, Lebanon;

${ }^{19}$ AL Zahraa Hospital, Rheumatology, Beirut, Lebanon; ${ }^{20}$ ZClinic, Rheumatology, Beirut, Lebanon; ${ }^{21}$ Weill Cornell Medicine, Rheumatology, Doha, Qatar

Background: Managing patients with chronic rheumatic diseases is increasingly relying on the collaboration of a multidisciplinary team, including the rheumatology nurse who can aid assessment of disease activity among other healthcare tasks.

However, this practice, although common in Europe and North America, is still poorly implemented in the Middle eastern Arab countries (MEAC).

Objectives: To evaluate the concordance between the physician's and the nurse's assessment of disease activity in patients with rheumatoid arthritis (RA) in the MEAC.

Methods: During a routine patient visit to one of 9 rheumatology clinics located in 7 Middle Eastern Arab countries, the physician and the rheumatology nurse (who was already working in the clinic) performed the disease activity score 28 (DAS), Clinical Disease Activity Index (CDAI) and Simple Disease Activity Index (SDAI) in a blinded manner. The concordance regarding the 3 continuous scores was calculated using paired t-test. The agreement between physicianand nurse-DAS categories (remission, low, moderate and high disease activity) was calculated using weighted kappa for category comparison. Predictive factors of positive concordance between physician- and nurse-DAS were identified using binary logistic regression

Results: The study included 373 patients' measurements over a period of two years (2018 to 2019). The mean age of the patients was 49.6 years $( \pm 28.2), 82.6 \%$ were females, and the mean disease duration was 11.3 years $( \pm 7.5)$.

The mean physician-DAS was slightly higher $(3.97( \pm 1.52))$ than the nurse-DAS $(3.90( \pm 1.54))(p=0.002)$, with a mean difference of $+0.08[95 \% \mathrm{Cl} 0.03 ; 0.12]$ (Table 1). The difference in the DAS individual items, the CDAI and the SDAI were not statistically significant.

When analyzing DAS as a categorical 4-items variable, the agreement between the physician and the nurse was present in $79.36 \%$ of the cases (weighted kappa was $0.77[95 \% \mathrm{Cl} 0.73 ; 0.83]$ which is considered as excellent, and was higher in patients with high disease activity (Figure 1).

A positive concordance between the physician- and the nurse-DAS was associated with the country (higher in Egypt, $p<0.001$ ) and the status of higher disease activity $(\mathrm{p}<0.001)$

Conclusion: The agreement between the DAS-28 performed by the physician and by the nurse was excellent and was associated with the country and a higher disease activity. The present study confirms that the support of a trained nurse for evaluating disease activity in RA is feasible in the Arab countries and may save some valuable time in the clinic, whilst maintaining the quality of care for patients with RA. 
Table 1. Comparison of the disease activity measures reported by the physician and by the nurse.

\begin{tabular}{lccc}
\hline & Physician & Nurse & p-value \\
\hline Total Joint Count & $4.87(2.26)$ & $5.02(6.20)$ & 0.152 \\
Swollen Joint Count & $2.13(3.88)$ & $2.15(3.83)$ & 0.790 \\
Global Assessment & $3.30(2.41)$ & $3.32(2.43)$ & 0.702 \\
DAS-28 & $3.97(1.52)$ & $3.90(1.54)$ & 0.002 \\
CDAl & $14.26(12.53)$ & $14.38(12.59)$ & 0.515 \\
SDAl & $21.51(23.57)$ & $21.61(21.66)$ & 0.527 \\
\hline
\end{tabular}

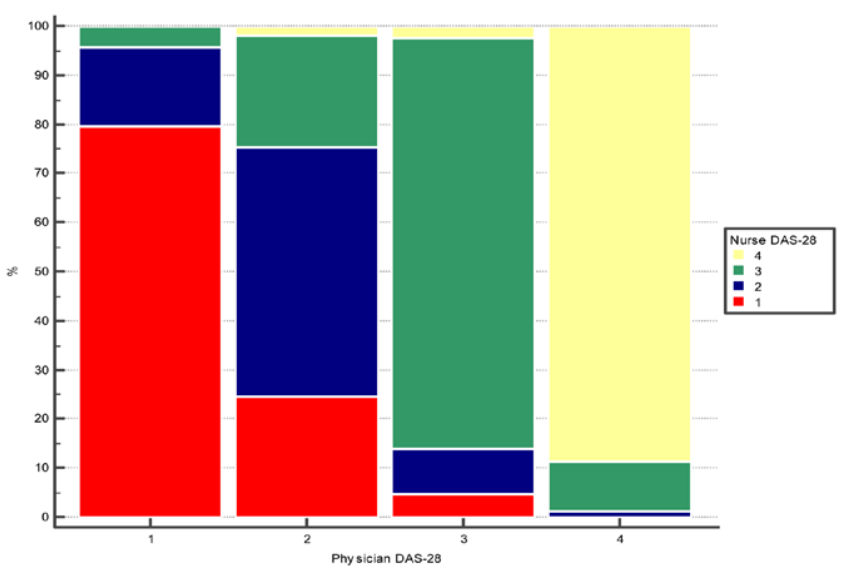

Figure 1. Agreement between physician- and nurse-DAS categories

Acknowledgements: The authors would like to acknowledge the patients for participating in the study and the assistants/ students/ nurses who assisted in the data collection: Dr. Fatima Abdul Majeed Al Hawaj, M. Atef Ahmed, M. Mohammad Alhusamiah, Ms Raquel De Guzman, Ms Lina Razzouk.

Disclosure of Interests: None declared

DOI: 10.1136/annrheumdis-2021-eular.650

\section{New drugs and therapies}

\section{POS0276 \\ EFFICACY OF KRILL OIL IN THE TREATMENT OF KNEE OSTEOARTHRITIS: A 24-WEEK MULTICENTRE RANDOMISED DOUBLE-BLIND CONTROLLED TRIAL}

L. Laslett ${ }^{1}$, L. Scheepers ${ }^{1}$, B. Antony ${ }^{1}$, A. Wluka ${ }^{2}$, C. Hill ${ }^{3,4}$, L. March ${ }^{5,6}$, H. Keen ${ }^{7}$, P. Otahal ${ }^{1}$, F. Cicuttini ${ }^{2}$, G. Jones ${ }^{1} .{ }^{1}$ University of Tasmania, Menzies Institute for Medical Research, Hobart, Australia; ${ }^{2}$ Monash University, Department of Epidemiology and Preventive Medicine, Melbourne, Australia; ${ }^{3}$ Rheumatology Unit, The Queen Elizabeth Hospital, Adelaide, Adelaide, Australia; ${ }^{4}$ The University of Adelaide, -, Adelaide, Australia; ${ }^{5}$ Royal North Shore Hospital, Department of Rheumatology, Sydney, Australia; ${ }^{6}$ University of Sydney, Kolling Inst., Inst. of Bone and Joint Res., Sydney, Australia; ${ }^{7}$ Fiona Stanley Hospital, School of Medicine and Pharmacology, Perth, Australia

Background: Elevated levels of systemic inflammation are common in people with osteoarthritis and predict both pain and structural outcomes. Krill oil has anti-inflammatory properties and reduces severity of inflammatory arthritis in mice by $50 \%$ compared to controls. ${ }^{1}$ In humans, krill oil reduced knee pain and function in two short, moderate quality randomised controlled trials (RCTs) in people with osteoarthritis. However, evidence from longer trials with imaging data is lacking.

Objectives: The aim of this study was to compare the efficacy of krill oil ( $2 \mathrm{~g} /$ day) vs. placebo for treating knee pain in patient with clinical knee osteoarthritis who have significant knee pain and effusion-synovitis.

Methods: KARAOKE was a 24-week multicentre, randomised, double-blind, placebo-controlled trial conducted at five Australian sites. Participants aged $\geq 40$ years with symptomatic knee OA (according to ACR criteria), significant knee pain (pain score $\geq 40 \mathrm{~mm}$ on a $100 \mathrm{~mm}$ visual analogue scale [VAS]), and effusion-synovitis present on MRI (grade $\geq 1$ according to modified Whole-Organ Magnetic Resonance Imaging Score (WORMS) scoring) were eligible. The study protocol has been published previously. ${ }^{2}$

Participants were randomised to receive $2 \mathrm{~g} /$ day of krill oil, $(350 \mathrm{mg} / \mathrm{g}$ omega- 3 content, $12 \mathrm{mg} / \mathrm{g}$ total omega- 6 content) or inert placebo (vegetable oil, no EPA or $\mathrm{DHA},<5 \mathrm{mg} / \mathrm{g}(0.05 \%)$ other omega- $3 \mathrm{~s})$.
The primary outcome was absolute change in knee pain assessed using a VAS [0-100mm] after 24 weeks. Secondary outcomes were: change in knee pain and function assessed using Western Ontario and McMaster Universities Osteoarthritis Index (WOMAC) score [0-500 mm]), change in back and hand pain assessed using a VAS [0-100mm], change in lower limb leg strength assessed using a dynamometer, and change in blood parameters (including CRP, triglycerides, fasting glucose and total, HDL, LDL cholesterol), after 24 weeks.

Linear mixed-models were used, using patient identification as random intercepts and trial centre and treatment month as random effect to adjust for correlated data within trial centres and repeated measures and to allow different treatment effects among patients over time, respectively.

Results: 262 participants were randomised (mean age 61.5 years, 53\% females) to receive krill oil $(n=130)$ or placebo $(n=132)$. A total of $85 \%$ completed the trial. Knee pain improved in both groups over 24 weeks, but with no betweengroup difference (krill oil, $-20.1 \mathrm{~mm}$; placebo, $-19.3 \mathrm{~mm}, \mathrm{p}=0.81$ ). Secondary outcomes: knee pain and function score improved in both groups, bu with no between-group difference (WOMAC pain: krill oil, -86.7; placebo, $-82.5 \mathrm{~mm}, \mathrm{p}=0.81$; WOMAC function: krill oil, -245.3; placebo, $-184.3, p=0.14$ at 24 weeks). The same applies for hand pain and back pain. No significant changes were seen in leg strength or any of the blood parameters at 24 weeks). Incidence of one or more adverse events was $50 \%$ in the krill oi group $(n=66)$ and $55 \%$ in the placebo group $(n=71)$. There were 8 serious adverse events in the krill oil group 6 in the placebo group, all considered unrelated to treatment.

Conclusion: Krill oil was safe and well tolerated, but did not significantly reduce knee pain in patients with clinical knee osteoarthritis, significant knee pain and effusion-synovitis after 24 weeks compared to placebo. These findings do not support use of krill oil for alleviating knee pain in clinical knee osteoarthritis.

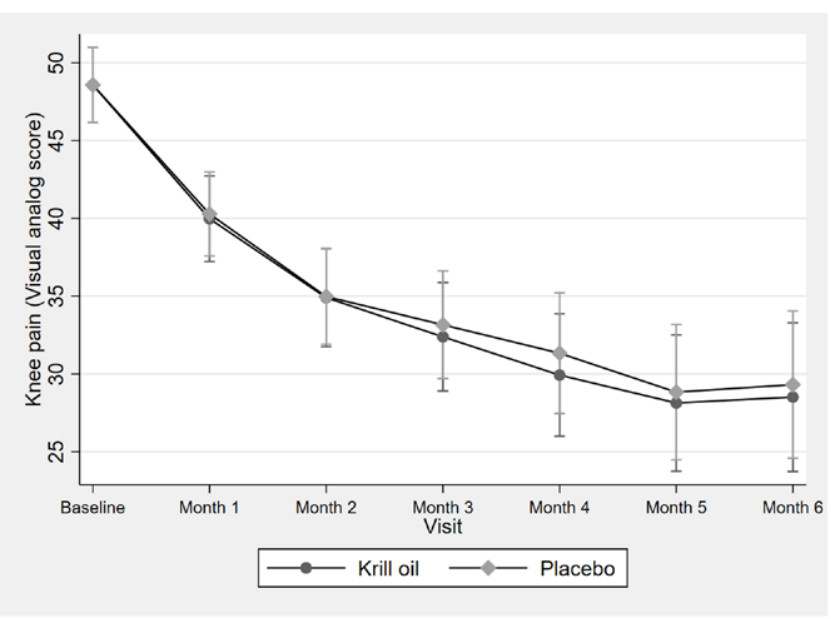

REFERENCES:

[1] lerna M, et al. BMC Musculoskelet Disord 2010;11:136.

[2] Laslett L, et al. Trials 2020;21:79

\begin{tabular}{lcc}
\hline Outcomes & Absolute between group difference at 24 weeks & $P$ value \\
\hline $\begin{array}{l}\text { Primary } \\
\text { Knee pain }\end{array}$ & $0.8(-5.6$ to 7.2$)$ & \\
Secondary & & 0.81 \\
Knee pain (WOMAC) & $4.2(-29.1$ to 37.5$)$ & 0.81 \\
Knee function (WOMAC) & $61(-19.2$ to 141.3$)$ & 0.14 \\
Hand pain & $2.8(-2.6$ to 8.3$)$ & 0.31 \\
Back pain & $1.9(-3.9$ to 7.8$)$ & 0.46 \\
Leg strength & $-2.59(-9.41$ to 4.23$)$ & 0.52 \\
Metabolic factors & & \\
Total Cholesterol & $0.09(-0.1$ to 0.29$)$ & 0.34 \\
HDL Cholesterol & $-0.03(-0.1$ to 0.03$)$ & 0.35 \\
LDL Cholesterol & $0.05(-0.12$ to 0.22$)$ & 0.57 \\
Triglycerides & $0.12(-0.09$ to 0.33$)$ & 0.27 \\
Fasting glucose & $0.01(-0.26$ to 0.29$)$ & 0.93 \\
hsCRP & $0.64(-0.56$ to 1.84$)$ & 0.30
\end{tabular}

Disclosure of Interests: Laura Laslett Speakers bureau: once, several years ago, and unrelated to this topic, Grant/research support from: Yes, received funding from Aker Biomarine to conduct this trial, Lieke Scheepers Shareholder of: AstraZeneca, Grant/research support from: Pfizer, unrelated to this topic Employee of: Previously employed by AstraZeneca, Benny Antony Speakers bureau: Zydus, Grant/research support from: Grant support for investigator-initiated trial from NR Ltd for unrelated research, Anita Wluka: None declared, 